\title{
A Coordinated Program of Library Instruction
}

\begin{abstract}
$\mathrm{A}$ $S$ A RESULT of reading the multitude of articles, theses, descriptions, and notes on the subject of library instruction to college and university students, ${ }^{1}$ two observations can be made. First, most instruction is planned on a class basis; that is, freshman orientation or reference instruction or special bibliographical courses. Second, most librarians approach the library by way of the book (form) while the user, often unconsciously, approaches the library by way of information (content). With these observations in mind, it seems worth while to summarize the recent experience at Lehigh University in planning and conducting a coordinated system of instruction based on information rather than the traditional book.

As this program was designed specifically for the situation at Lehigh, the setting is briefly described. The university library has approximately 350,000 volumes, with open stacks and a liberal lending policy. During regular sessions the building is open 82 hours a week, with reference service available for 77 hours. There are two unsupervised special collections on metallurgy and chemistry outside the building and a number of laboratory or office collections. The university has approximately 2,600 male undergraduates, 60 per cent in the Col-

1 See the following for summaries of library instruction programs: J. D. Lee, "Instruction in the Use of Books and Libraries in Colleges and Universities" Books and Libraries in Colleges and Universities"
(Master's thesis, Kent State University, 1951); M. C. Marquis, "Study of the Teaching of Library Facilities to College Students" (Master's thesis, George Peabody College, 1952).
\end{abstract}

Mr. Taylor is assistant librarian, Lehigh University. lege of Engineering, which includes chemistry and physics, and 40 per cent divided between the College of Arts and Sciences and the College of Business Administration. There are some 500 graduate students, both men and women, in 18 departments. In 1955, 20 doctoral degrees were awarded in departments ranging from Physics to English.

There are a number of basic assumptions in our approach to the student:

1. The student must know what a library is and its relation to his needs before he can learn how to use it. Most students will not be scholars. It is necessary, therefore, to recognize the need of an educated man (define him as you will) who understands the need to verify facts and to extend individual knowledge, whether he is in business, technology, science, politics, or scholarship.

2. Locating information in a library is highly complex. Even librarians, presumably trained in information sources, sometimes have difficulty locating specific bits of information. We cannot expect the faculty member or the serious student to know all possible sources. The users are not usually interested in techniques of filing, classification, or cataloging, and have to be oriented in these matters.

3. As librarians we are prone to assume the supremacy of the book. This assumption is no longer valid. The book today is merely one of the forms of available information storage.

4. Some students may view the librarian as an ineffectual person who is concerned with a trivial and harmless sort of activity. As a result of this caricature, 
earned or unearned, librarians have had to demonstrate their usefulness to beginning students.

5. A library instruction period, or course, can do little to arouse a "love for books." Either the student has such a love when he comes to college or the milieu of the four years' educational process, of which the library is a part, provides the proper setting for its development. It cannot be taught.

With the outlined assumptions in mind an eclectic program was developed. Other librarians will recognize bits and pieces of their own work. We believe, however, that our approach to the student is valid and that the coordination of all facilities directed to instructional purposes will in time show positive and measurable results. Our program was as follows:

1. Library personnel would give all instruction, because faculty members are likely to be concerned primarily with their specialties.

2. Freshmen would receive a one-hour lecture and tour of the library, with particular emphasis on the complexity of information and the services of a library.

3. Juniors and seniors in specified departments would receive instruction in the information sources of their particular fields.

4. Graduate students would receive special instruction in the bibliographical sources and the information problem in their respective fields.

5. The reference department would function as an integral part of follow-up instruction.

The freshmen lectures are arranged in cooperation with the English department and include some thirty sections of about twenty students, each spread over a two-week period. The lecture is followed by a student "research paper." Four points are stressed: (a) a library is information, (b) there is a certain order in the information as it is placed in the building, (c) information is complex and it comes in many forms, and (d) the reference staff is present to help the student. These points are discussed, first generally and then in context at Lehigh. What is information? How do we use it? What forms does it come in?

After this introduction, the freshmen are taken on the usual tour of the major points in the building. The emphasis is placed on the why and what of a library, rather than how to use it. The technique of use is not avoided. It merely plays second role to the raison d'être of a library. The students see how a divided catalog works by examining the entries in both catalogs under a particular name. They see the various approaches in the catalogs to one book. A discussion of the flow of work in the technical services division shows the students the variety of work involved and the cost necessary to get a book to them. By seeing some of the less-used abstracting and indexing journals, such as Current List of Medical Literature, Nuclear Science Abstracts, Economics Abstracts, and the Patent Office Gazette, the students receive some idea of the sources available and the problem of finding specific information in them. Comparisons of a bound volume of the New York Times and its equivalent on microfilm and of a periodical with a microcard edition of it, give the students some idea of problems of storage and costs. These microreproductions show them that there are forms of information storage other than the book.

In summary, the following things are partially accomplished by the freshman library instruction: the student knows where the library is; he knows something of the internal layout of the building; he has some concept of what a library is and the problems in administering it; he has some idea of information and the role it plays in everyday life; he sees techniques for using the catalog; 
and he knows the library staff is present to help him.

An exhibit on the library and information during the period of the freshman lectures helps to emphasize the intent of the program. In 1954, for instance, the methods of recording man's experience were traced from the cuneiform record on clay tablets to the cathode-ray tube and included the palmleaf book of Ceylon, Greek papyrus, the medieval manuscript, the printed book, the photograph, the microfilm, and the punched card. A special exhibit panel borrowed from the American Institute of Biological Sciences showed the operation of the Rapid Selector in the Department of Agriculture Library.

Library handbooks are still used, but they seem to be an expensive and littleused medium. Large illustrated guides at the various catalogs and other trouble points would be more effective. Instead of the handbook, the freshman would receive a mimeographed outline of the major points of the lecture emphasizing the relations between information and the indexes, catalogs, and bookstacks.

On the upper-class level, when students are beginning to specialize, the instruction system is changed to meet the particular demands of the subject. At the time the system was established, we decided to approach first those departments which were traditionally the smallest users of the library: industrial, mechanical, mining, and chemical engineering. The results were, if not spectacular, highly gratifying. To these departments were added, as time permitted, geology, education, speech, metallurgical engineering, electrical engineering, government, and international relations. Others will be added as they can be fitted in. The lecture is scheduled as part of a regular course: in some cases a two-hour laboratory period, in others a 50-minute lecture period.

A two-page mimeographed sheet of "Information Tips" is compiled by the reference staff for each subject giving the following data: major professional handbooks; major indexes or bibliographies; special information sources available, such as trade catalogs, corporation annual reports, directories, encyclopedias, biographical dictionaries; major current journals received in the subject; peculiarities of the subject catalog in the field.

In the lecture, the four points of the freshman instruction-information, order, complexity, and the reference staff - are repeated, with emphasis on the particular subject. Some of the aspects of machine control and information analysis are discussed. With electrical engineers, the possible application of information theory to library systems is briefly presented.

With the assistance of the course instructor, an information problem is devised and used as a basis for examining the various sources of information in the library. In chemical engineering, for instance, a particular problem chosen was "liquid-liquid extraction as applied in the petroleum industry." With the class, the instructor searched the KirkOthymer Encyclopedia of Chemical Technology, Chemical Abstracts, the subject catalog, and various handbooks. Several books or parts of books, one or two articles, and a patent were noted. Under the guidance of the librarian-instructor, the class traced the items through the various catalogs to see if the library had them and, if so, where they were located.

The third type of instruction is on the graduate level. So far, the departments of biology, geology, and civil engineering have participated. Many points of the freshman and upper-class instruction are repeated because of the diversity of graduate student background. The problem of information is discussed on a more sophisticated level, pointing out, for example, the intricacies and complexities of government and institutional research reports and their indexing (if any). Spe- 
cific bibliographical sources are examined and, if justified, a search for information is made.

Interwoven through the entire system of library instruction is the emphasis on the reference staff. It is the policy of the readers' service division that, within the limits of good sense and available time, any student or faculty member searching for information should leave the building either with the information desired, or satisfied that the information is not available. Of course, this is an extravagant statement, but it represents an ideal. The object is to move the library out of the warehouse level to a newer information pattern.

The reference department uses three methods to extend the intent of the library lectures:

1. Individual instruction in the use of the catalogs and periodical indexes at the time a question is asked.

2. A postcard which the questioner addresses to himself if the question is intricate or time is short. When time permits, the questions are worked on and the cards posted.

3. A worksheet filled out in consultation with the reference staff for students working on reports or theses. This is basically a guide to sources the student might search for the information he wants. The sheet lists particular subject headings in the main catalog; specific periodical indexes with some indication as to subjects; bibliographies to search; or reference books.

A series of special subject guides to the library's collections provides a second extension of the instructional program. These guides are a result of a fifteenmonth study of reference questions, which indicated subjects causing particular pressure on the reference staff.

The instructional system is by no means perfect. Continual adjustment and criticism by the library staff bring changes every year. More time for lec- tures and more follow-up reports by the courses are needed. These will come in time. The pattern is established and accepted by the faculty. Cooperation from the faculty was forthcoming only because they were convinced that the situation required it and the students needed it. This took time, patience and an understanding of teaching needs. Everything was not done at once. The work described was accomplished over a three-year period.

Our object in the library instruction system is to relate the user to information: to give him an idea of the complexities of information systems such as a library and to show him how the library can be a vital source of information. What we are trying to do is establish a pattern of habits that will lead the student and later citizen to information sources to verify or extend his knowledge. In our judgment, we have partially succeeded.

There may be a criticism that the system described is valid only for Lehigh University, where a majority of the students major in engineering or in the physical sciences. The system cannot be lifted in toto and placed in another situation. We believe, however, that our approach to the problem of library instruction is valid. The mass of information exists in sociology, government, history, and psychology as well as in chemistry. The study of logic and languages, traditionally subjects of the humanities, is becoming increasingly important in information analysis. In many cases, the indexing services in the social sciences (if they exist at all) lag far behind the comprehensive indexing projects, such as Chemical Abstracts, in the sciences, yet the amount of available knowledge is just as vast. For these reasons, the approach to instruction on the basis of information rather than the book (content rather than form) is applicable to the social sciences and the humanities, as well as to the sciences and technology. 